\title{
INFORMASI AKUNTANSI MANAJEMEN DAN KEEFEKTIFAN PENGAMBILAN KEPUTUSAN
}

\author{
Hernawan \\ Program Studi IImu Akuntansi, Fakultas Ekonomi Universitas Tanjung Pura, Kalimantan Barat
}

\begin{abstract}
Abstrak
Penelitian ini adalah untuk mengungkapkan data yang empiris tentang faktor yang mempengaruhi dominasi informasi akuntansi manajemen yang terdiri dari: informasi akuntansi penuh, informasi akuntansi diferensial dan akuntansi pertanggungjawaban untuk menyusun laporan perencanaan, laporan kontrol dan laporan informasi dan efektivitas pengambilan keputusan. Metode penelitian ini adalah Metode Survey Explanatory dan melakukan pengumpulan data dengan kuesioner kepada 138 perusahaan yang dikategorikan sebagai industri berskala besar diproduksi di Kalimantan Barat data. Data dianalisis dengan analisis jalur. Hasil penelitian ini adalah: (1) informasi lengkap akuntansi, informasi akuntansi diferensial, informasi akuntansi pertanggungjawaban: (a) faktor yang paling dominan yang mempengaruhi laporan perencanaan informasi akuntansi penuh, (b) faktor yang paling dominan yang mempengaruhi untuk mengendalikan laporan adalah informasi akuntansi pertanggungjawaban, (c) faktor yang paling dominan yang mempengaruhi laporan informasi adalah informasi akuntansi diferensial, (2) faktor yang paling dominan yang berpengaruh terhadap pengambilan keputusan efektivitas informasi akuntansi penuh, (3) faktor yang paling dominan perencanaan laporan, laporan mengendalikan dan melaporkan informasi yang berpengaruh terhadap pengambilan keputusan efektivitas laporan informasi.
\end{abstract}

Kata Kunci: Informasi akuntansi penuh, informasi akuntansi diferensial, informasi akuntansi pertanggung-jawaban, perencanaan laporan, laporan kontrol, laporan informasi dan efektivitas pengambilan keputusan.

\begin{abstract}
This research is to reveal empiric data about the dominance factor that influences management accounting information that consists of: full accounting information, differential accounting information and responsibility accounting to compose of planning report, control report and informational report and to the effectiveness of decision making. The method of this research is Explanatory Survey Method and conducted data collecting by questionnaire to 138 companies those categorized as big scale manufactured industries in West Kalimantan. The data analyzed by path analysis. The result of this study are: (1) full accounting information, differential accounting information, responsibility accounting information: (a) The most dominance factor that influence to planning report is full accounting information; (b) The most dominance factor that influence to controlling report is responsibility accounting information, (c) The most dominance factor that influence to informational report is differential accounting information; (2) The most dominance factor that influence to decision making effectiveness is full accounting information; (3) The most dominance factor of planning report, controlling report and informational report that influence to decision making effectiveness is informational report.
\end{abstract}

Keywords: full accounting information, differential accounting information, responsibility accounting information, planning report, control report, informational report and to the effectiveness of decision making. 


\section{PENDAHULUAN}

Lingkungan bisnis cenderung terus berubah dan sangat kompetitif, sebagai akibat dari era globalisasi (Naisbitt, 2007; Laudon dan Laudon, 2007). Kondisi tersebut juga terjadi di Asia, dimana saat ini lingkungan bisnis di Asia dalam kondisi sangat kompetitif. Perubahan yang sangat cepat yang terjadi di China dan memberikan pengaruh signifikan terhadap liberalisasi perdagangan di seluruh Asia (Williamson, 2005). Implikasinya, perusahaan di kawasan Asia termasuk Indonesia dihadapkan pada kondisi persaingan yang ketat, karena masing-masing bebas untuk mengembangkan diri, memasuki pasar dan berkompetisi. Persaingan yang ketat juga akibat adanya inovasi yang tiada henti hingga menyebabkan produk mutakhir setiap hari masuk pasar tanpa batas (Kazali, 2007; Neisbit, 2007).

Sehubungan dengan hal tersebut terdapat tiga tantangan informasi yang dihadapai oleh para eksekutif, yaitu (1) apa, kapan dan bentuk informasi yang dibutuhkan, (2) bagaimana memperoleh, menguji dan mengkombinasikan informasi serta mengintegrasikannya ke dalam kesatuan informasi yang utuh, (3) pemrosesan data dan sistem akuntansi perlu dilaksanakan secara bersama-sama untuk mengurangi ketidakbermaknaan dan meningkatkan keseimbangan (Laudon dan Laudon, 2006; McLeod dan Schell, 2006). Dampak dari hal tersebut maka akuntansi menjadi bidang yang paling menantang, khususnya akuntansi manajemen karena paling cepat mengalami perubahan.

Perusahaan manufaktur di Kalimantan Barat didominasi oleh Industri Hasil Pertanian dan Kehutanan (IHPK) yang pada tahun 2006 menyumbang 98,48\% terhadap nilai ekspor Kalimantan Barat. Berturut-turut sumbangan yang dominan diberikan oleh industri perkayuan $73,60 \%$, industri karet $17,89 \%$, industri makanan 4,29 dan sisanya dari industri perabot kayu
1,10\% dan komoditi IHPK lainnya 1,60 (Deperin Kalimantan Barat, 2007). Khusus mengenai industri pengolahan kayu yang berjumlah 60 dari jumlah perusahaan di Kalimantan Barat (BPS, 2006) dan potensi ini diupayakan untuk terus memberikan sumbangan yang signifikan terhadap Pendapatan Domestik Regional Brnto (PDRB).

Terkait dengan hal tersebut, penelitian ini merujuk pada penelitian yang dilakukan oleh Lillis dan Mundy (2005) yang menunjukkan bahwa akuntansi manajemen merupakan jaringan penghubung yang sistematis dalam penyajian informasi yang berguna dan dapat daya untuk membantu pimpinan perusahaan dalam usaha mencapai tujuan organisasi yang telah ditetapkan sebelunmya. Informasi akuntansi manajemen ini terdiri dari full accounting information, differential accounting information, dan responsibility accounting information. Jika informasi akuntansi manajemen dihubungkan dengan objek informasi seperti produk yang dihasilkan departemen/divisi dan aktivitas perusahaan, maka dihasilkan informasi akuntansi lengkap. Pengambilan keputusan tentang pemilihan beberapa altematif pada akuntansi diferensial dapat dikelompokkan menjadi dua, yaitu: Keputusan jangka panjang dan keputusan jangka pendek. Keputusan jangka panjang merupakan keputusan yang diambil manajer, dimana hasil dari keputusan tersebut dapat memberikan manfaat yang lebih dari satu tahun (Graham, King, dan Bailes, 2004).

Hasil penelitian lain yang dijadikan acuan adalah penelitian Dikolli dan Sedatole (2007) yang menyimpulkan bahwa Informasi yang digunakan manajemen sebagai dasar pengambilan keputusan adalah informasi akuntansi manajemen dan merupakan informasi utama yang dimiliki perusahaan. Informasi akuntansi manajemen terutama digunakan oleh 
pimpinan perusahaan di dalam menunjang pelaksanaan fungsi-fungsi manajemen khususnya fungi perencanaan dan pengawasan.

Selanjutnya penelitian Dhavale (2007) menyimpulkan bahwa jenis-jenis informasi akuntansi manajemen, yaitu: (1) informasi akuntansi lengkap; (2) informasi akuntansi diferensial, dan (3) informasi akuntansi pertanggungjawaban. Jika informasi akuntansi manajemen dihubungkan dengan altematif yang akan dipilih, maka akan dihasilkan konsep informasi akuntansi diferensial, yang sangat diperlukan oleh manajemen dalam pengambilan keputusan pemilihan altematif. Jika informasi akuntansi manajemen dihubungkan dengan wewenang yang dimiliki oleh manajer, maka akan dihasilkan konsep informasi akuntansi pertanggungjawaban, yang terutama manfaat untuk mempengaruhi perilaku manusia dalam organisasi.

Berdasarkan uraian tersebut, maka penelitian ini menelaah faktor yang mempengaruhi efektivitas informasi akuntansi manajemen dan kemudian dikaji bagaimana pengaruhnya terhadap keefektifan pengambilan keputusan. Hal tersebut didasarkan pada fenomena bahwa informasi akuntansi manajemen yang dihasilkan tersebut digunakan sebagai dasar pengambilan keputusan oleh para manajer di seluruh tingkatan, yaitu digunakan untuk memutuskan hal-hal yang berkaitan dengan perencanaan, koordinasi, pengendalian aktivitas, penyusunan informasi keuangan untuk semua tingkatan manajemen. Keefektifan pengambilan keputusan ditinjau dari: (1) Dasar kekuasaan manajerial, (2) Hubungan manajer dan bawahan, dan (3) Kondisi keputusan yang diambil dan masalah yang dipecahkan (Cooke \& Slack, 1991; Jogiyanto, 2005a; Laudon dan Jane, 2005; McLeod dan Schell, 2006).

Tujuan penelitian ini adalah untuk menganalisis mengenai: (1) Pengaruh efektivitas informasi akuntansi manajemen yang meliput efektivitas informasi akuntansi lengkap, diferensial, dan pertanggung-jawaban terhadap efektivitas perencanaan laporan, pengendalian laporan, dan laporan informasi pada perusahaan industri manufaktur di Kalimantan Barat; (2) Pengaruh efektivitas informasi akuntansi lengkap, diferensial, dan pertanggungjawaban terhadap efektivitas pengambilan keputusan pada perusahaan industri manufaktur di Kalimantan Barat; dan (3) Pengaruh perencanaan laporan, pengendalian laporan, dan laporan informasi terhadap efektivitas pengambilan keputusan pada perusahaan industri manufaktur di Kalimantan Barat.

\section{KERANGKA PEMIKIRAN}

Accounting Management Information Theory dari Balakishnan dan Sivaramakrishnan (2002), Anthony (2003), Dhavale (2007), Chapman, Hopwood dan Shields (2007). Teori ini menyatakan bahwa Informasi akuntansi manajemen dapat membantu manajemen mengidentifikasikan suatu masalah, menyelesaikan masalah, dan mengevaluasi kinerja. Informasi akuntansi manajemen dibutuhkan dan digunakan dalam semua lingkup manajemen, meliputi perencanaan. pengendalian dan pengambilan keputusan. Dalam suatu proses perencanaan dan pengendalian diperlukan informasi sebagai kumpulan fakta, data, pengamatan, persepsi atau manusia yang lain, yang relevan dengan aktivitas perusahaan.

Informasi diperlukan untuk mengurangi ketidakpastian dalam pengambilan keputusan, karena pengambilan keputusan selalu menyangkut masa yang akan datang, yang mengandung ketidakpastian, dan selalu menyangkut pemilihan suatu alternatif tindakan di antara sekian banyak alternatif yang tersedia. Karena itu pengambilan keputusan dalam perusahaan juga selalu berusaha mengumpulkan informasi untuk mengurangi ketidakpastian yang dihadapi dalam memilih alternatif tindakan tersebut. 
Terkait dengan konsep di atas, Wikipedia The Free Ecyclopedia merinci berbagai tipe informasi yang diperlukan oleh pengambil keputusan (en.wikipedi.org/wiki/ full_cost_accounting, 2006). Tipe informasi yang dimaksud dapat disajikan pada Gambar 1.

Akuntansi dapat dipandang sebagai suatu sistem mengolah masukan berupa data operasi dan data keuangan untuk menghasilkan keluaran berupa informasi akuntansi yang dibutuhkan oleh pemakai. Sesuai dengan pihak-pihak yang menggunakan informasi.

Informasi akuntansi manajemen memiliki tiga tujuan, yaitu: (1) Menyediakan informasi guna perhitungan harga pokok jasa, produk, dan tujuan lain yang diinginkan manajemen; (2) Menyediakan informasi guna perencanaan, pengendalian, pengevaluasian, dan perbaikan berkelanjutan; dan (3) Menyediakan informasi guna pengambilan keputusan (Hansen dan Mowen, 2005; Laudon dan Laudon, 2006; Mcleod dan Schell, 2006).

Decision Making Theory, dari Beach (1993); Wolk et al., (1993); Choe, (2004b); Dhavale (2007), mempertanyakan tentang informasi apa yang dibutuhkan untuk pengambilan keputusan. Keputusan (decision) berarti pilihan (choice), yaitu pilihan dari dua atau lebih kemungkinan. Keputusan sebagai sebuah kesimpulan yang dicapai sesudah dilakukan pertimbangan, yang terjadi setelah satu kemungkinan dipilih, sementara yang lain dikesampingkan. Pertimbangan yang dimaksud adalah menganalisis beberapa kemungkinan atau alternatif dan pemilihan satu diantara alternatif tersebut berdasarkan informasi. Dibalik keputusan ada unsur prosedur, yaitu: identifikasi masalah, klarifikasi tujuan khusus yang diinginkan, pemeriksaan kemungkinan untuk mencapai tujuan yang telah ditetapkan dan penetapan pilihan bertindak. Pengambilan keputusan adalah aspek yang paling penting dari kegiatan manajemen yang merupakan kunci dari kepemimpinan. Masa depan suatu organisasi banyak ditentukan oleh pengambilan keputusan sekarang. Keputusan yang diambil bukan hanya keputusan-keputusan mengenai kebijaksanaan pokok yang rumit, tetapi juga pengambilan keputusan yang berkaitan dengan pelaksanaan program, penempatan, dan penganggaran, merupakan titik-titik kritis terhadap efektifnya suatu kebijaksanaan.

Berdasarkan pandangan di atas, karakteristik pengambilan keputusan diuraikan Scott, dan Gyllenstedt, (2007), sebagai berikut: (1) Dasar kekuasaan manajerial, diukur dari pola terbentuknya legitimasi kekuasaan manajerial; (2) Hubungan manajer dengan bawahan, diukur dari kualitas hubungan formal dan informal antara manajer dengan bawahan; (3) Kondisi tugas dan keputusan yang diambil, diukur dari Rasionalisasi penyelesaian tugas dan realisasi keputusan yang diambil; (4) Proses pengambilan keputusan, diukur dari intensitas pemenuhan kaidah pengambilan keputusan yang sesuai dengan metode ilmiah.

Hal tersebut mengindikasikan bahwa mengambil keputusan memerlukan sejumlah tindakan dan langkah-langkah yang dilakukan secara sistematis. Hal tersebut sejalan dengan konsep yang mengemukakan bahwa decision making is the process of making choices. Pembuatan keputusan ini dinilai sebagai pusat aktivitas dari seluruh manajemen (Graham, King, dan Bailes, 2004).

peranan informasi akuntansi manajemen dalam sektor manufaktur yaitu: membantu proses desain produk sehingga dapat lebih efisien, memberikan tanda kapan perlunya peningkatan kualitas, efisiensi, kecepatan dalam operasi manufaktur, memandu keputusan product mix, memilih supplier dan bemegosiasi tentang harga, tampilan, kualitas, pengiriman produk (Choe. 2004).

Penelitian ini terutama ditekankan pada bagaimana informasi yang dapat dikuantifikasikan, yaitu informasi akuntansi manajemen yang dihasilkan dapat membantu manajemen dalam mengambil keputusan. Jadi kualitas informasi akuntansi manajemen 
ditentukan oleh bermanfaat tidaknya informasi yang disajikan tersebut dalam membantu manajemen untuk pengambilan keputusan.

Karakteristik di atas memberikan gambaran bahwa efektivitas laporan intern berupa laporan manajemen, ditentukan oleh dilengkapi tidaknya kriteria informasi akuntansi yang efektif di atas. Efektivitas informasi akuntansi manajemen berpengaruh pada perusahaan dalam mencapai tujuan, guna mencapai suatu tujuan setiap keputusan harus didukung oleh informasi yang benar, akurat dan dapat dipertanggungjawabkan. Sehingga pencapaian sasaran yang diharapkan dapat meningkatkan efektivitas IAM.

Melihat pentingnya informasi akuntansi manajemen dihubungkan dengan pengambilan keputusan manajemen, maka jelaslah bahwa laporan intern yang efektif mempunyai peranan untuk menghasilkan pengambilan keputusan yang efektif (Ward, 1996; Beach, 1993; Graham, King, dan Bailes, 2004; Dhavale, 2007; Dikolli, dan Sedatole, 2007).

Penelitian ini mengukur kekuatan faktor yang mempengaruhi keefektifan informasi akuntansi manajemen sesuai kriteria yang telah ditetapkan. Apabila kriteria yang telah ditetapkan dibandingkan dengan hasil pelaksanaan telah sesuai, maka dapat dikatakan informasi tersebut telah efektif. Efektivitas adalah kualitas, kuantitas, hasil pelayanan, penggunaan waktu, atau pencapaian pelaksanaan lainnya dengan membandingkan suatu standard yang telah ditentukan lebih dahulu (Graham, King, dan Bailes, 2004; Dhavale, 2007).

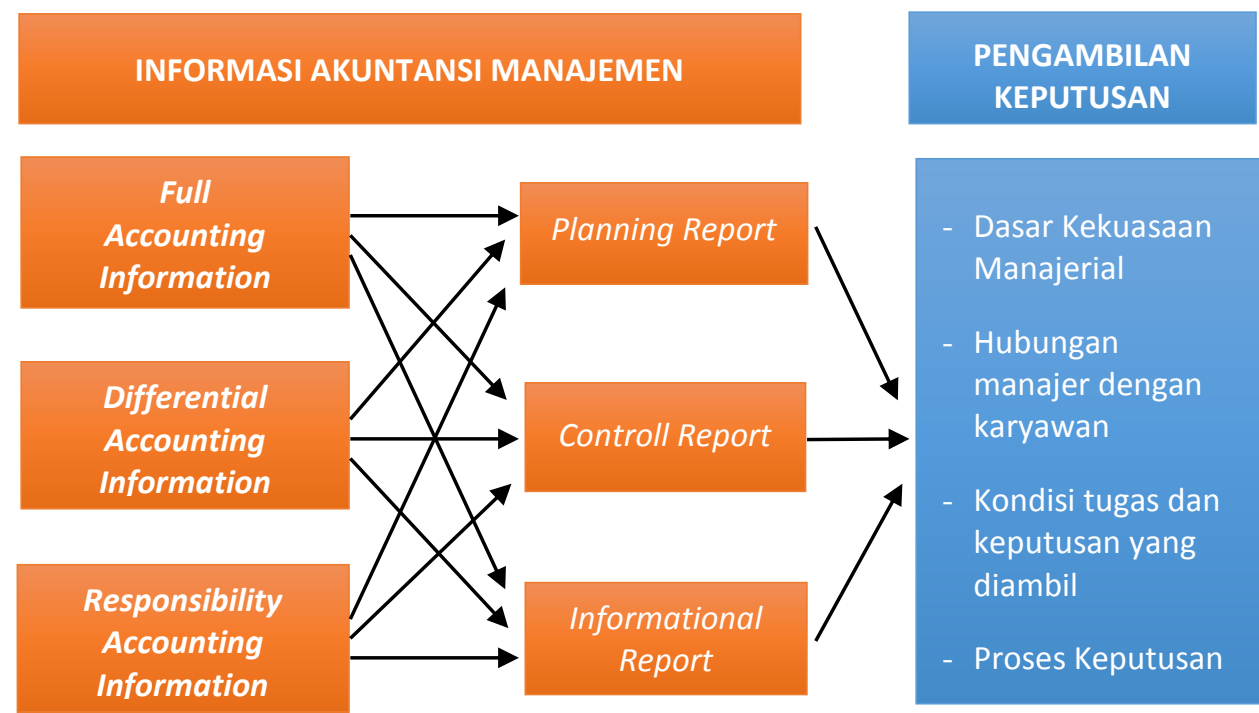

\section{Gambar 1}

\section{Paradigma Penelitian}

Berdasarkan paradigma tersebut hipotesis yang diuji dalam penelitian ini: (1) Efektivitas informasi akuntansi manajemen yang meliputi efektivitas informasi akuntansi lengkap, diferensial, dan pertanggung-jawaban berpengaruh positif dan signifikan terhadap efektivitas perencanaan laporan, pengendalian laporan, dan laporan informasi; (2) Efektivitas informasi akuntansi lengkap, diferensial, dan pertanggungjawaban berpengaruh positif dan signifikan terhadap efektivitas pengambilan keputusan; dan (3) Laporan perencanaan, laporan pengendalian, dan laporan informasional berpengaruh positif dan signifikan terhadap efektivitas pengambilan keputusan. 


\section{METODE PENELITIAN}

Penelitian ini menggunakan Metode Survei Penjelasan (Explanatory Survey Method). Metode ini dibatasi pada pengertian survei sampel yang bertujuan menguji hipotesis yang telah dirumuskan sebelumnya (Singarimbun, 1993; Kerlinger, 1995; Sekaran, 2005; Cooper, 2006; Arikunto, 2006). Walaupun uraiannya juga mengandung deskripsi, tetapi sebagai penelitian relasional fokusnya terletak pada penjelasan hubungan antar variabel, konsekuensinya diperlukan operasionalisasi variabel yang lebih mendasar kepada indikatornya. Variabel penelitian dioperasionalisasikan mengacu pada semua variabel laten (latent variable) dan variabel manifes (manifest variable) yang terkandung dalam hipotesis.

Variabel penelitian dioperasionalisasikan mengacu pada semua variabel laten (latent variable) dan variabel manifes (manifest variable) yang terkandung dalam hipotesis.

Populasi penelitian ini meliputi faktor yang mempengaruhi keefektifan IAM dan keefektifan pengambilan keputusan, keefektifan Informasi akuntansi manajemen dan keefektifan pengambilan keputusan. Sedangkan sasarannya adalah perusahaan industri manufaktur berskala besar di Kalimantan Barat. Ukuran sampel penelitian ditentukan oleh bentuk analisis yang digunakan sesuai dengan hipotesis yang diajukan. Ukuran sampel dalam penelitian ini 138 perusahaan. Selanjutnya menentukan proporsi menurut jenis industri, yaitu 138 perusahaan.

Data yang dikumpulkan terdiri dari data primer dan sekunder, data primer dari 138 responden, masing-masing Responden mewakili 1 Perusahaan, yaitu (1) Direktur Utama=18 orang dan (2) yang diberi Kuasa oleh Direktur Utama, teridiri dari (a) Direktur Keuangan=28 orang; (b) Direktur Produksi $=25$ orang; (c) Direktur $\mathrm{SDM}=10$; (d) Direktur Pemasaran=27 orang; (e) Departemen Riset, Teknologi, dan Infomasi (RISTI)=13 orang; dan (f) Kepala Divisi Teknologi dan Informasi $=17$ orang. Sedangkan data sekunder diperoleh dari Deperin dan BPS Kalimantan Barat.

Teknik pengumpulan data dilakukan dengan teknik komunikasi tidak langsung dengan instrumen penelitian berupa kuesioner dan studi dokumenstasi. Jenis kuesioner yang digunakan adalah kuesioner tertutup. Analisis data yang digunakan dalam penelitian ini adalah analisis deskriptif untuk melihat karakteristik sampel yang terjaring dalam penelitian ini dan SEM (Structural Equation Modeling).

\section{HASIL \& PEMBAHASAN}

Hasil penelitian mengenai tanggapan responden atas masing-masing variabel penelitian mengenai deskripsi dari masingmasing variabel dapat dijelaskan sebagai berikut:

Tabel 1

Kondisi IAM, Keefektipan IAM, dan PK

\begin{tabular}{lccc}
\hline \multicolumn{1}{c}{ Variabel } & Skor Aktual & Skor Ideal & (\%) \\
\hline Informasi Akuntansi Manajemen (IAM) & 16.927 & 23.460 & 72,16 \\
\hline 1. Informasi Akuntansi lengkap (IAL) & 10.735 & 13.800 & 77,79 \\
\hline 2. Informasi Akuntansi Diferensial (IAD) & 2.777 & 4.830 & 57,49 \\
\hline 3. Informasi Akuntansi Pertanggungjawaban (IAP) & 3.415 & 4.830 & 70,70 \\
\hline Keefektifan Informasi Akuntansi Manajemen (IAM) & 13.016 & 18.630 & 69,87 \\
\hline 1. Laporan Perencanaan (LPR) & 4.342 & 6.210 & 69,92 \\
\hline 2. Laporan Pengendalian (LPG) & 4.320 & 6.210 & 69,57 \\
\hline 3. Laporan Informasional (LI) & 4.354 & 6.210 & 70,11 \\
\hline Keefektifan Pengambilan Keputusan (PK) & 13.686 & 19.320 & 75,22 \\
\hline
\end{tabular}




\begin{tabular}{cll}
\hline Variabel & Skor Aktual & Skor Ideal \\
\hline Pengujian hipotesis pertama yang dilakukan & manajemen dengan produk laporan keuangan, \\
\hline dengan menggunakan Strucutural Equation & terbukti dapat diterima.
\end{tabular}

Modeling (SEM) program LISREL untuk menguji adanya hubungan antara informasi akuntansi

Tabel 1

Hasil Pengujian Hipoesis Pertama

\begin{tabular}{|c|c|}
\hline & $\begin{array}{r}\text { Laporan Peren } \\
\text { (LPR) }\end{array}$ \\
\hline Informasi Akuntansi lengkap (IAL) & $.95(p=.00$ \\
\hline Informasi Akuntansi Diferensial (IAD) & $.76(p=.00$ \\
\hline $\begin{array}{l}\text { Informasi Akuntansi } \\
\text { Pertanggungjawaban (IAP) }\end{array}$ & $.84(p=.00$ \\
\hline \multicolumn{2}{|l|}{ Sumber: Output SEM dengan Program Lisrel } \\
\hline $\begin{array}{l}\text { Demikian halnya pengujian hi } \\
\text { yaitu: Laporan Perencanaan } \\
\text { Pengendalian (LPG), dan Laporan } \\
\text { (LI) secara parsial dan simultar } \\
\text { terhadap Pengambilan Keputus } \\
\text { dapat diterima. }\end{array}$ & $\begin{array}{l}\text { tesis ke dua, } \\
\text { २), Laporan } \\
\text { formasional } \\
\text { perpengaruh } \\
\text { Keputusan }\end{array}$ \\
\hline
\end{tabular}

Tabel 3

Hasil Pengujian Hipotesis Ke dua

\begin{tabular}{lcccc}
\hline Variabel & $\begin{array}{c}\text { Loading } \\
\text { Factor }\end{array}$ & $\mathrm{R}^{2}$ & $\begin{array}{c}\text { Error } \\
\text { Varians }\end{array}$ & Kesimp. \\
\hline $\mathrm{LPR} \rightarrow \mathrm{PK}$ & .71 & .504 & .496 & $\mathrm{H}_{\mathrm{o}}:$ Riject \\
\hline $\mathrm{LPG} \rightarrow \mathrm{PK}$ & .85 & .723 & .278 & $\mathrm{H}_{\mathrm{o}}:$ Riject \\
\hline $\mathrm{IA} \rightarrow \mathrm{PK}$ & .78 & .608 & .392 & $\mathrm{H}_{\mathrm{o}}:$ Riject \\
\hline
\end{tabular}

Sumber: Hasil Analisis LISREL

Pengujian hipótesis ketiga, informasi akuntansi lengkap, informasi akuntansi dieferensiasi, dan informasi akuntansi pertanggungjawaban secara parsial dan simultan berpengaruh terhadap keefektifan pengambilan keputusan dapat diterima.

Tabel 4

Hasil Pengujian Hipotesis Ketiga

\begin{tabular}{lcccc}
\hline Variabel & $\begin{array}{c}\text { Loading } \\
\text { Factor }\end{array}$ & $\mathrm{R}^{2}$ & $\begin{array}{c}\text { Error } \\
\text { Varians }\end{array}$ & Kesimp. \\
\hline $\mathrm{IAL} \rightarrow \mathrm{PK}$ & .81 & .656 & .344 & $\mathrm{H}_{\mathrm{o}}:$ Riject \\
\hline $\mathrm{IAD} \rightarrow \mathrm{PK}$ & .71 & .504 & .496 & $\mathrm{H}_{\mathrm{o}}:$ Riject \\
\hline $\mathrm{IAP} \rightarrow \mathrm{PK}$ & .61 & .372 & .628 & $\mathrm{H}_{\mathrm{o}}:$ Riject \\
\hline
\end{tabular}

Sumber: Hasil Analisis LISREL

Secara keseluruhan pengaruh informasi akuntansi manajemen terhadap laporan keuangan, laporan keuangan terhadap pengambilan keputusan serta informasi akuntansi manajemen terhadap pengambilan keputusan dapat dijelaskan pada Tabel 5.

Tabel 5

Hasil Pengujian Hipotesis

\begin{tabular}{lcccc}
\hline Variabel & $\begin{array}{c}\text { Loading } \\
\text { Factor }\end{array}$ & $\mathrm{R}^{2}$ & $\begin{array}{c}\text { Error } \\
\text { Varians }\end{array}$ & Kesimp. \\
\hline $\mathrm{IAM} \rightarrow \mathrm{LK}$ & 0,95 & 0,91 & 0,09 & $\mathrm{H}_{\circ}:$ Riject \\
\hline $\mathrm{LK} \rightarrow \mathrm{PK}$ & 0,52 & 0,53 & 0,47 & $\mathrm{H}_{\circ}:$ Riject \\
\hline $\mathrm{IAM} \rightarrow \mathrm{PK}$ & 0,80 & 0,16 & 0,84 & $\mathrm{H}_{\mathrm{o}}:$ Riject \\
\hline
\end{tabular}

Sumber: Hasil Analisis LISREL.

Efektivitas informasi akuntansi manajemen yang meliputi informasi akuntansi lengkap, diferensial, dan pertanggungjawaban berpengaruh positif dan signifikan terhadap efektivitas perencanaan laporan, pengendalian laporan, dan laporan informasi pada perusahaan 
industri manufaktur di Kalimantan Barat. (a) Informasi akuntansi lengkap merupakan aspek yang dominan berpengaruh terhadap laporan perencanaan yang efektif; (b) informasi akuntansi pertanggungjawaban yang dominan berpengaruh terhadap laporan pengendalian; dan (c) informasi akuntansi diferensial merupakan aspek yang dominan berpengaruh terhadap laporan informasional. Hasil penelitian ini didukung oleh pengujian hipotesis ini sejalan dengan teori dari yang dikemukakan oleh Balakishnan dan Sivaramakrishnan (2002), Anthony (2003), Dhavale (2007), Chapman, Hopwood dan Shields (2007), yang menyatakan bahwa Informasi akuntansi manajemen dapat membantu manajemen mengidentifikasikan suatu masalah, menyelesaikan masalah, dan mengevaluasi kinerja. Informasi akuntansi manajemen dibutuhkan dan digunakan dalam semua lingkup manajemen, meliputi laporan perencanaan, laporan pengendalian dan laporan informasional. Dalam suatu proses perencanaan, pengendalian, dan informasional diperlukan informasi sebagai kumpulan fakta, data, pengamatan, persepsi atau manusia yang lain, yang relevan dengan aktivitas perusahaan.

Efektivitas informasi akuntansi manajemen yang meliputi informasi akuntansi lengkap, diferensial, dan pertanggungjawaban berpengaruh positif dan signifikan terhadap efektivitas pengambilan keputusan pada perusahaan industri manufaktur di Kalimantan Barat.

Informasi akuntansi lengkap merupakan aspek yang dominan berpengaruh terhadap keefektifan pengambilan keputusan. Hasil penelitian ini, sejalan dengan teori yang dikemukakan oleh Ward, 1996; Beach, 1993; Balakishnan dan Sivaramakrishnan 2002; Anthony 2003; Graham, King, dan Bailes, 2004; Dhavale, 2007; Dikolli, dan Sedatole, 2007; Chapman, Hopwood dan Shields (2007), bahwa Informasi akuntansi manajemen dapat membantu manajemen mengidentifikasikan suatu masalah, menyelesaikan masalah, dan mengevaluasi kinerja guna pengambilan keputusan. Informasi akuntansi manajemen dibutuhkan dan digunakan dalam semua lingkup manajemen termasuk pengambilan keputusan yang meliputi (1) dasar kekuasaan manajerial; (2) hubungan manajerial; (3) kondisi tugas yang diambil; (4) proses pengambilan keputusan.

Perencanaan laporan, pengendalian laporan, dan laporan informasi berpengaruh positif dan signifikan terhadap efektivitas pengambilan keputusan pada perusahaan industri manufaktur di Kalimantan Barat. Laporan informasional merupakan factor yang dominan berpengaruh terhadap efektifan pengambilan keputusan. Hasil penelitian ini didukung oleh pengujian hipotesis dan sejalan dengan teori yang dikemukakan oleh Ward, 1996; Beach, 1993; Graham, King, dan Bailes, 2004; Dhavale, 2007; Dikolli, dan Sedatole, 2007, yang melihat pentingnya informasi akuntansi manajemen dihubungkan dengan pengambilan keputusan manajemen, maka jelaslah bahwa laporan intern yang efektif mempunyai peranan untuk menghasilkan efektifitas pengambilan keputusan yang meliputi (1) dasar kekuasaan manajerial; (2) hubungan manajerial; (3) kondisi tugas yang diambil; (4) proses pengambilan keputusan.

\section{KESIMPULAN}

Efektivitas informasi akuntansi manajemen yang meliputi informasi akuntansi lengkap, diferensial, dan pertanggungjawaban berpengaruh positif dan signifikan terhadap efektivitas perencanaan laporan, pengendalian laporan, dan laporan informasi pada perusahaan industri manufaktur di Kalimantan Barat. (a) Informasi akuntansi lengkap merupakan aspek yang dominan berpengaruh terhadap laporan perencanaan yang efektif; (b) informasi akuntansi pertanggungjawaban yang dominan berpengaruh terhadap laporan pengendalian; dan (c) informasi akuntansi diferensial merupakan aspek yang dominan berpengaruh terhadap laporan informasional. 
Efektivitas informasi akuntansi manajemen yang meliputi informasi akuntansi lengkap, diferensial, dan pertanggungjawaban berpengaruh positif dan signifikan terhadap efektivitas pengambilan keputusan pada perusahaan industri manufaktur di Kalimantan Barat. Informasi akuntansi lengkap merupakan aspek yang dominan berpengaruh terhadap keefektifan pengambilan keputusan.

Perencanaan laporan, pengendalian laporan, dan laporan informasi berpengaruh positif dan signifikan terhadap efektivitas pengambilan keputusan pada perusahaan industri manufaktur di Kalimantan Barat. Laporan informasional merupakan factor yang dominan berpengaruh terhadap efektifan pengambilan keputusan.

\section{DAFTAR PUSTAKA}

Alavi, Maryam; Yoo, Youngjin; Vogel, Douglas R. 1997. Using information Technology to add value to management education. Academy of Management Journal, Vol: XL No: 61997 p: 1310-1333.

Anthony, R. N. 2003. Management-Recounting: A Personal History. Journal of Management Accounting Research (15): 249-253.

Arya, A., J. C. Fellingham and D. A. Schroeder, 2004. Aggregation and Measurement Errors in Performance Evaluation. Journal of Management Accounting Research (16): 93105.

Atkinson, Martin, 1997. Organization in the network age information Technology and Organization: Strategies, network, and Integration, Journal of Technology Analysis \& Strategic Management (TAS) ISSN: 0953 7325 Vol: DC Date: Decembre 1997 p : 489 491.

Balakishnan, R. and K. Sivaramakrishnan. 2002. A Critical Overview of the use of full-cost data for planning and pricing. Journal of
Management Accounting Research (14): 331.

Banker, R. D., G. Potter and R. G. Schroeder. 1993. Reporting manufacturing Performance measures to workers: An Empirical study. Journal of Management Accounting Research (5): 33-55.

Beach, Lee Roy, 1993. Making the Right Decision: Organization Culture, Vision and Planning. Englwood Cliffs, New Jersey: Prentice Hall.

Choe, Jong-min, 2004. Impact of Management Accounting Information and AMT on Organizational Performance. Journal of Information Technology, Volume 19, Number 3, September 2004 , pp. 203214(12)

Dhavale, D. G. 2007. Product Costing For Decision Making in Certain Variableproportion technologies. Journal of Management Accounting Research (19): 5170 .

Dikolli, S. S. and K. L. Sedatole. 2007. Improvements in the information content of nonfinancial forward-looking Performance measures: A taxonomy and empirical application. Journal of Management Accounting Research (19): 71-104 .

Emerson, John. 1998. Information Technology : The key to successful 1: 1 Relationship. Journal of Managed Healthcare (MHR) ISSN : 1060-1392 Vol :Vm Date: April 1998 p : 16 $-21$.

Fay, Judy, 1997. Information Technology in Practising Firms. Journal of Accountancy Ireland (ACCI), ISSN: 0001-4699, Vol: XXIX Date-Decembre 1997 p: 20-21.

Freund, Bruno ; Konig, Herbert ; Roth, Norbert 1997. Impact of Information Technologies on Manufacturing. International Journal of Technology Management (ITN), ISSN: 02675730 Vol- XIII 1997 n- 215-228.

Guven-Uslu, Pinar, 2007. Uses of Management Accounting Information for Benchmarking in NHS Trusts. Journal of Public Money \& 
Management. August 2007. Vol. 28, Issue 4, pp. 239-246,

Hull, Richard, 1997. Information Technology and Changes in Organisational Work. Journal of Management Studies (JMS) ISSN 0022 2380, Vol: XXXIV, Date: January 1997 p : 164 -167 .

Krumwiede, Kip R; Roth, Harold P, 1997. Implementing Information Technology Innovations: Me Activity Based Costing Example, SAM Advanced Management Journal (AMJ) ISSN: 0749-7075 Vol : LXHDate: Autumn 1997 p: 4-12+.

Laudon, Kenneth C., and Jane P. Laudon., 2006. Management Information Systems: Managing the Digital Firm. $10^{\text {th }}$ Edition. Prentice Hall

Leach-Lopez, M A., W. W. Stammerjohn and F. M McNair. 2007. Differences in The Role of Job-Relevant Information in The Budget Participation-Performance Relationship Among U.S. and Mexican Managers: A Question of Culture or Communication. Journal of Management Accounting Research (19): 105-136.

Leithch, Robert A. and Davis K. Roscoe, 1993. Accounting Information Systems, Englewood Cliffs, New Jersey: Prentice Hall Inc.

Lillis, A. M. and J. Mundy. 2005. Cross-Sectional Field Studies in Management Accounting Research - Closing The Gaps Between Surveys and Case Studies. Journal of Management Accounting Research (17); 119-141.

Lingle, John H. and William A Sciemann, 1996. From Balanced Scorecard to is Measurement. American Management Association, Maret 1996. p.56-61.

Lucas Jr, Henry C., 1992. Information Systems Concepts for Management. Student Edition. Tokyo: Me. Graw Hill Kogakusha Ltd.

Maciag, Gregory A, 1997. Shortage Of Information Technology Professionals Will Drive Cooperation. Journal of National Underwriter (Life/Health/Financial Services)
ISSN 0893 - 8202 Vol: Cl Date: December 1997 p: 43.

Mahmood, Mo Adam, 1997. How Information Technology Resources Affect Organizational Performance and Productivity. Information Resources Management Journal ( RMJ ), ISSN 1040 - 1628, Vol: X Date:Winter 1997 p: 4-5.

Me Kinnon, Sharon M and William J, Bruns, Jr., 1997. What Production Managers Really Want to Know. Reading In Management Accounting. International Edition. By S. Mark Young. New Jersey: Prentic Hall, Inc.

Mintzberg, H., and B.Austin, 1997. Strategy Formation In Adhocracy. Journal of Administrative Sience Quarterly. 1997 p: 160-197.

Moscove, Stephen and Mark G. Simkin 1981. Accounting Information Systems: Concepts and Practice for Effective Decision Making. New York: John Wiley and Sons me.

Mukhopadhyay, Tridas; Rajiv,Surendra; Srinivasan, Kannan, (1997). Information Technology impact on process output and quality, Journal of Management Science (MCI), ISSN : 0025 - 1909 Vol: XLffI Date: Decembre 1997 p: 1645-1659.

Nanni, Alfred J., Dixon, and Volman, (1997). Integrated Performance Measurement: Management Accounting To Support The New Manufacturing Realities. Journal of Management Accounting Research 1997 p: 1-17.

Radcliffe, Voughan S. David R. Campbell, Timothy J. Fogarty., 2003. Case Study in User of Accounting Information. Journal of Management Accounting Research (JMAR). 2003, Volume 13

Raisinghani, Mike S; Ramarapu, Narender K; Simkin, Mark G., 1998. The Impact of Technology on Cooperative Groups. Journal Information Systems Management (JIF), ISSN: 1058-0530 Vol: XV Date: Summer 1998 p: 40-46. 
Romney, Marshall B., dan Paul John Steinbart., 2006. Accounting Information System. $9^{\text {th }}$ Edition. Prentice Hall.

Sciulli, Nick., 2004.The Use of Management Accounting Information to Support Contracting out Decision Making in The Public Sector. Journal Qualitative Research in Accounting and

Shields, M. D. 2005. Introductory note: Jerry Feltham: management accounting revolutionary. Journal of Management Accounting Research (16): 143.

Tarn, Kar Yan, 1998. The Impact of Information Technology Investment on Firm Performance and Evaluation: Evidence From Newly Industrialized Economies. Information Systems Research (ISR): A Journal of The Institute of Management Sciences (ISR), ISSN: 1047-7047, Vol: DC Date: March 1998 p: 85-98.

Wang, Shouhong., 1997. Impact of Information Technology on Organizations. Journal of Human Systems Management (HSM), ISSN: 0167 - 2533 Vol: XVI 1997 p: 83-90 